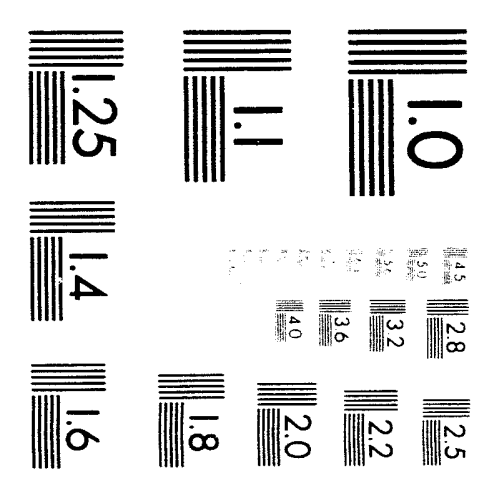



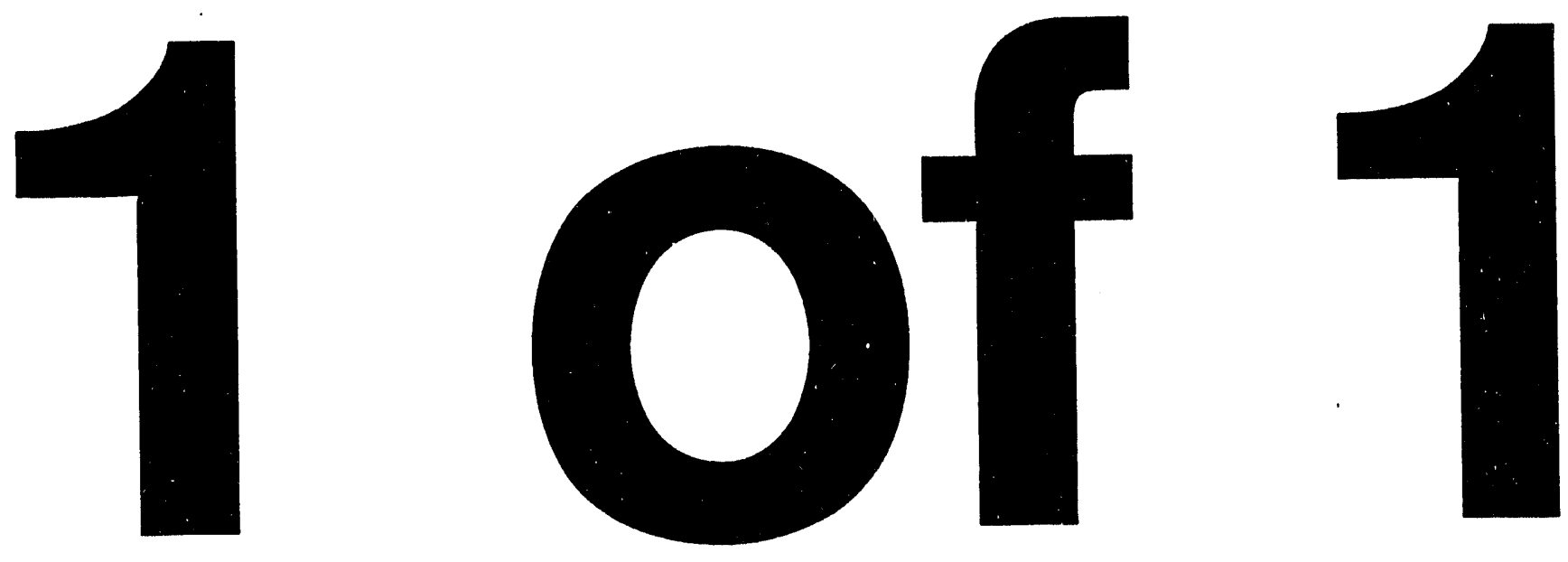
LA.UR- $93-\mathbf{3} 807$

Title:

Author(s):

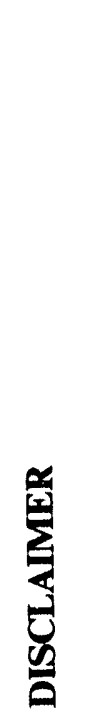

Submitted to:
A SPACE FIBET-OPTIC X-RAY BURST DETECTOR

C. E. Moss, D. E. Casperson, SST-9

M. A. Echave, J. R. Miller, W. W. Saylor, M. R. Sweet, B. C. Edwards \& J. E. Valencia, SST-9

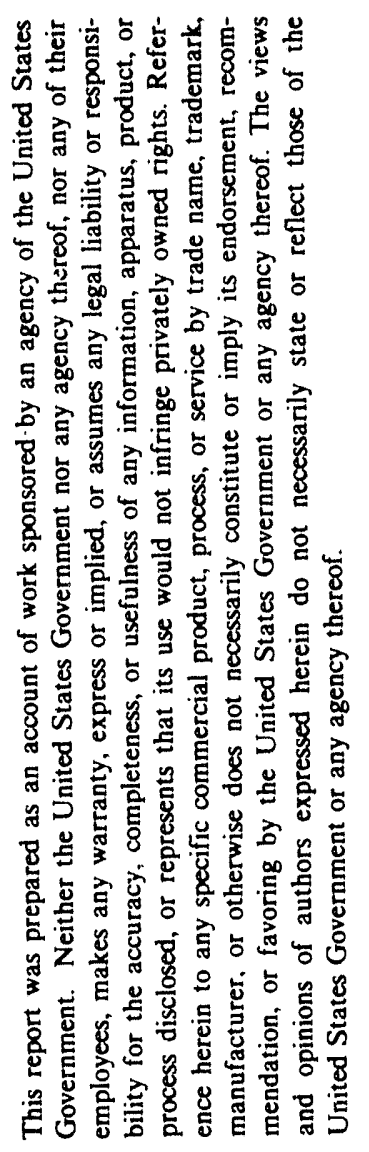

IEFE 1993 Conference, Nuclear Science Symposium and Medical Imaging Conference, San Francisco, CA

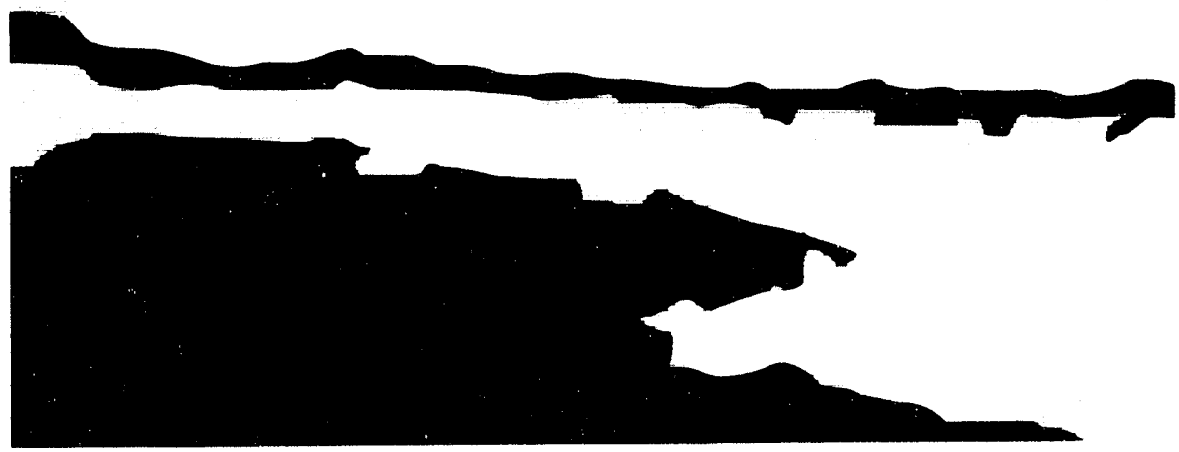

Los Alamos National Laboratory, an affirmative action/equal opportunity employer, is operated by the University of California for the U.S. Department of Energy under contract W-7405-ENG-36. By acceptance of this article, the publisher recognizes that the U.S. Government retains a nonexclusive, royalty-free license to publish or reproduce the published form of this contribution, or to allow others to do so, for U.S. Government purposes. The Los Alamos National Laboratory requests that the publisher identify this article as work performed under the auspices of the U.S. Department of Energy. 


\title{
A Space Fiber-Optic X-Ray Burst Detector
}

\author{
C. E. Moss, D. E. Casperson, M. A. Echave, B. C. Edwards, J. R. Miller, \\ W. W. Saylor, M. R. Sweet, and J. E. Valencia \\ Los Alamos National Laboratory
}

\section{Abstract}

We describe a novel, lightweight $x$-ray burst detector that can be embedded in a satellite structure, thus forming a "smart skin," which has minimal impact on the host satellite. The design is based on two types of optical fibers coupled to photodiodes. The first is a scintillating fiber, which gives a fast signal for timing. The second is a germanium-doped silica fiber, which darkens for a few milliseconds when irradiated with a burst of $x$ rays. The resulting slow signal is used to discriminate against electrostatic discharges. The coincidence of a fast signal from the scintillating fiber with a slow signal from the darkening fiber is the signature of an $\mathrm{x}$-ray burst. The response is linear at low doses and becomes nonlinear at high doses. We have two techniques to test the instrument in a space experiment scheduled for 1994. First , a small, space-qualified flash $x$-ray unit can illuminate the fibers. Second, we can detect space background radiation. The cumulative dose will be monitored by RADFET dosimeters. Future work on embedding the fibers and the electronics as Application Specific Integrated Circuits (ASICs) in the spacecraft skin could lead to use of these detectors on many satellites.

\section{INTRODUCTION}

To warn of attack and assess damage by nuclear detonations (NUDETs), the Strategic Defense Initiative (SDI) satellites need detectors located on the satellites. In response we have chosen to develop an $x$-ray detector because of the large burst $x$-ray output from a NUDET. Traditional $x$-ray instruments such as scintillators on photomultipliers, proportional counters, and semiconductor counters are susceptible to false events due to electrostatic discharges (ESD) caused by spacecraft charging and due to space radiation. The rate of such events can be reduced by operating several such sensors in coincidence, but then the instruments become too massive for widespread use. We describe a novel, lightweight $\mathrm{x}$-ray detector that can be embedded in satellite structure, thus forming a "smart skin," which has minimal impact on the host satellite.

The concept will be tested with an instrument built for the Satellite Attack Warning Assessment Flight Experiment (SAWAFE), to be flown on the one-year STEP 3 mission. The instrument will be part of a nadir-pointing, load-bearing panel on a spacecraft supplied by TRW (Fig. 1). The panel is a polyetherimide honeycomb core sandwiched between a glass/polycyanate front face and a graphite/polycyanate back face. Launch by a Pegasus rocket into $a=450-\mathbf{k m}$ altitude orbit inclined at $>65^{\circ}$ is scheduled for 1994. The instrument will collect calibration and space background data during the mission. An overview of SAW AFE including the present $x$-ray detector, an RF detector, and a laser detector is available[1].

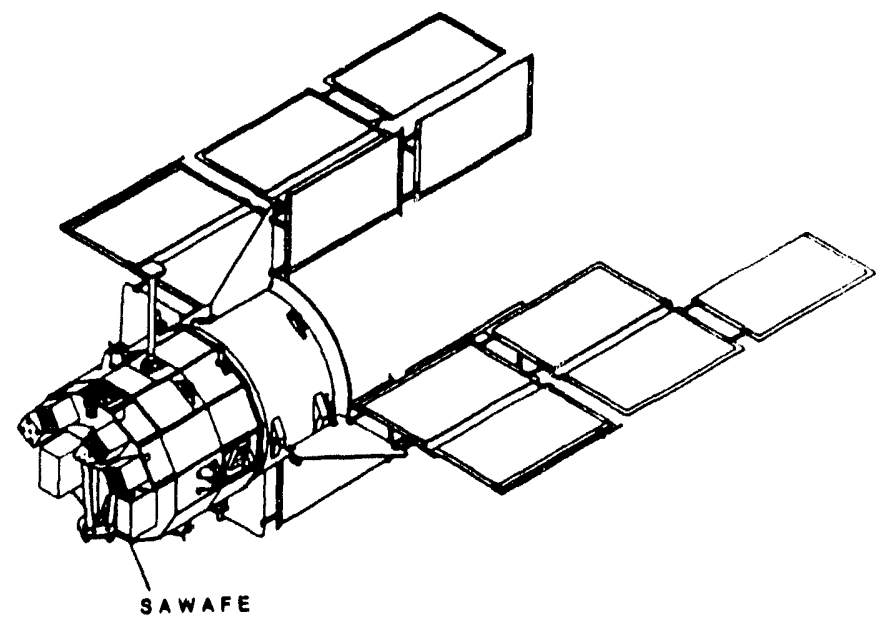

Fig. 1. STEPMission 3 spacecraft. The SAWAFE panel is on the bottom, which is nadir pointing.

\section{INSTRUMENT DESCRIPTION}

\section{A. Fibers}

Our SAWAFE design is based on two types of optical fibers used as $\mathrm{x}$-ray sensors. The first is a $500-\mu \mathrm{m}$ (diam) $\times 4-\mathrm{m}$ (length) Bicron BCF-28 scintillating fiber coupled to a silicon photodiode, which gives a fast signal to determine the precise time of arrival of the burst at the satellite. The length is about three times the $1 / \mathrm{e}$ length of $1.25 \mathrm{~m}$ for scintillation light. The second is a 100- $\mu \mathrm{m}$-core $\times$ 64-m-long multimode germanium-doped silica fiber (Coming 1508), which darkens for a few milliseconds when irradiated with a burst of $x$ rays [2]. This darkening phenomenon, being much slower than the few microseconds expected in electrostatic discharges caused by spacecraft charging, can be used to confirm that a signal was produced by an $x$-ray burst. The coincidence of a fast signal from the scintillating fiber with a slow signal from the darkening fiber is the signature of an $x-r$ ay burst.

The mounting of the fibers on the spacecraft panel is shown in Fig. 2. The fibers are attached with structural adhesive as single-thickness coils on top of the spiral RF antenna, which is a separate experiment on SAWAFE. The ends of the fibers are fed through close-fitting teflon tubing potted with low-outgassing, space-qualified epoxy into slots in the panel and sealed on the 
back side at the end of each tube with a drop of epoxy. This method of mounting the fibers allows then to be replaced if necessary.

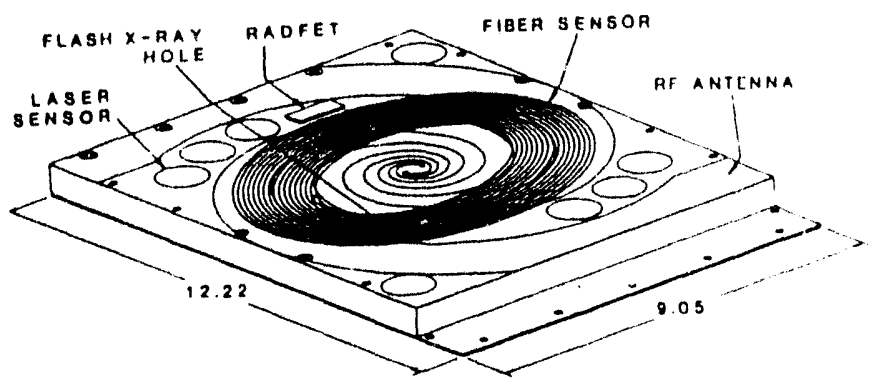

Fig. 2. SAWAFE panel. The flash $x$-ray unit mounted at the back of the panel illuminates the fibers through the flash $\mathrm{x}$-ray hole. The laser sensors and RF antenna are separate experiments.

A scintillating fiber sensor is based on the same principle as an ordinary scintillator sensor but with important differences due to the geometry. The fiber can be made to conform to complicated surfaces. Light produced in the scintillating fiber can be transmitted several meters through a non-scintillating fiber, such as Bicron BCF-98, to shielded avionics interior to the spacecraft, thus reducing ESD and EMI problems. For BCF-98 fibers a few meters long, the attenuation, scintillation due to incident radiation, and the darkening due to radiation damage are negligible.

\section{B. Coatings}

The scintillating fiber is coated with $100 \mu \mathrm{m}$ of Chemglaze Z306, which is a nonconducting black paint, to keep out sunlight. The darkening fiber is not affected by sunlight. A nonconducting paint was selected because metallic coatings such as aluminium or beryllium would have degraded the performance of the $R F$ antenna under the fibers. The coating was kept thin in order to avoid attenuating the incident $x$ rays but still provides a neutral density optical filter value of 11 . The paint was applied in many thin coats by rotating a straight fiber in a fixture and scanning a spray gun along the fiber. The whole panel except for the laser sensors is coated with $40 \mu \mathrm{m}$ of white Chemglaze A276 for thermal control of the spacecraft. The spacecraft requirements of the panel are $-4^{\circ} \mathrm{C}$ to $50^{\circ} \mathrm{C}$. The scintillating fiber is of particular concern because the softening point is $70^{\circ} \mathrm{C}$.

The white Chemglaze is coated with $150 \AA$ of indium tin oxide (ITO) to mitigate two potential problems. First, since Chemglaze is an excellent electrical insulator, ESD might produce spurious signals $[3,4]$ or cause a light leak in the scintillating fiber coating. The TTO coating is slightly conducting with a resistivity of $150 \mathrm{k} \Omega$ per square that will bleed off charge to the grounded screws fastening the panel to the spacecraft. Second, Chemglaze is eroded by atomic oxygen ( $A O)$. In a $\approx 450-\mathrm{km}$ orbit and for an average look direction Chemglaze Z306 (black) is eroded at $=8 \mu \mathrm{m} / \mathrm{yr}(80 \mu \mathrm{m} / \mathrm{yr}$ at sunspot maximum, $0.8 \mu \mathrm{m} / \mathrm{yr}$ at sunspot minimum)[5]. Chemglaze A276 (white) erodes at approximately one third the rate of $\mathrm{Z306}$. We are unaware of any specific information on ITO, but based on LDEF data on $\mathrm{SiO}_{2}$ [6], we expect it to be unaffected by $\mathrm{AO}$. Because gold is known
(1) be unaffected by $A O[7]$ and is a good conductor, we initially tried 50 $A$ of gold. We rejected this coating because the solar spectrum thermal absorptance increased from 0.28 for bare $\mathrm{A} 276$ to 0.7 after corating with gold (Table 1). ITO did not change the abscirptance.

Table 1

Coating Effects

\begin{tabular}{|c|c|c|c|}
\hline $\begin{array}{c}\text { Coating } \\
\text { Material }\end{array}$ & $\begin{array}{c}\text { Coating } \\
\text { Thickness }(\AA)\end{array}$ & Absorptance & Reflectivity \\
\hline None & 0 & 0.28 & 0.86 \\
\hline ITO & 150 & 0.28 & 0.89 \\
\hline Gold & 50 & 0.70 & 0.87 \\
\hline
\end{tabular}

\section{Flash X-Ray Unit}

A small, space-qualified flash $\mathbf{x}$-ray unit (Fig. 3) mounted on the back side of the panel illuminates the fibers through a hole and provides a functional test of the instrument. The unit, developed by Golden Engineering, Inc., is approximately $7 \mathrm{~cm}$ (dia) $\times 15 \mathrm{~cm}$ (length) and weighs about $1100 \mathrm{~g}$. A small, external DC-to-DC converter charges an internal capacitor to about 8000 $V$. A free-running spark gap connects this energy to an $x$-ray tube via a voltage multiplying circuit. The repetition rate is limited to about one pulse every 15 seconds by the limited power on the spacecraft. In space the unit will only be used to provide a few pulses per hour because the expected lifetime of the tube is $<10^{5}$ pulses. The output is about $1 \mathrm{mr} /$ pulse at $30 \mathrm{~cm}$ from the source. This unit also has terrestrial applications such as field radiography.
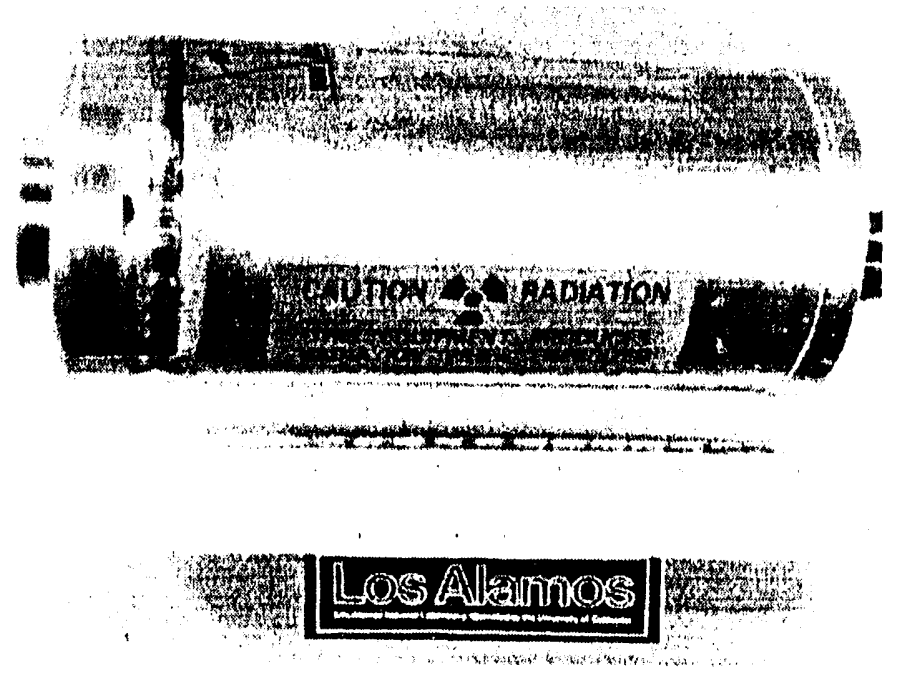

Fig. 3. Flash $x$-ray unit.

\section{RADFET Dosimeter}

The calculated dose from space radiation in the STEP 3 orbit at $\approx 450 \mathrm{~km}$ and $>65^{\circ}$ is $>100 \mathrm{krad}(\mathrm{Si}) / \mathrm{yr}$. High doses cause some permanent damage to the fibers, which, in principle, can be used to measure the absorbed dose but, in practice, is difficult because of transient effects and annealing. The SAWAFE instrument will 
include a RADFET dosimeter[8,9] supplied by REM in ( ) x ford, UK, to independently measure the dose. This device is based on a metal-oxide-semiconductor ficld-effect transistor. Radiation causes space charge to be formed and trapped in the oxide insulator and at the oxide-silicon interface under the gate electrode. This shifts the threshold voltage required to operate the gate by an amount proportional to the dose until close to saturation. The oxide thickness is $0.13 \mu \mathrm{m}$, which gives a response of $\approx 17 \mathrm{mV} / \mathrm{krad}(\mathrm{Si})$. During irradiation the gate can be either biased or not biased, but the calibration, in general, is different for each mode. The SAW AFE RADFET will be unbiased, except during readout, to conserve power even though the biased mode is less temperature and dose-rate dependent and more linear. Biasing during readout is provided by a current of $90 \mu \mathrm{A}$.

\section{E. Electronics}

The mechanical design of the avionics system is based on a "slice" architecture (Fig. 4). Each slice is approximately 10 inches $x 9$ inch $\times 1.29$ inch (thickness) and is comprised of an exterior metal frame and two printed circuit boards. Each slice includes a connector for the 32-bit processor global bus, power, and ground connections. Each detector subsystem is built into one or more slices. The slices required by the $x$-ray detector are the $x$-ray slice, which contains the analog and digital boards, the processor and solid state memory slice, and the power supply slice. A complete avionics box is formed when the slices for all the instrumerits are placed together, end plates are attached, and bolts are run from one end to the other. The design allows for rapid prototyping and fabrication of tlight experument (omp)nents.

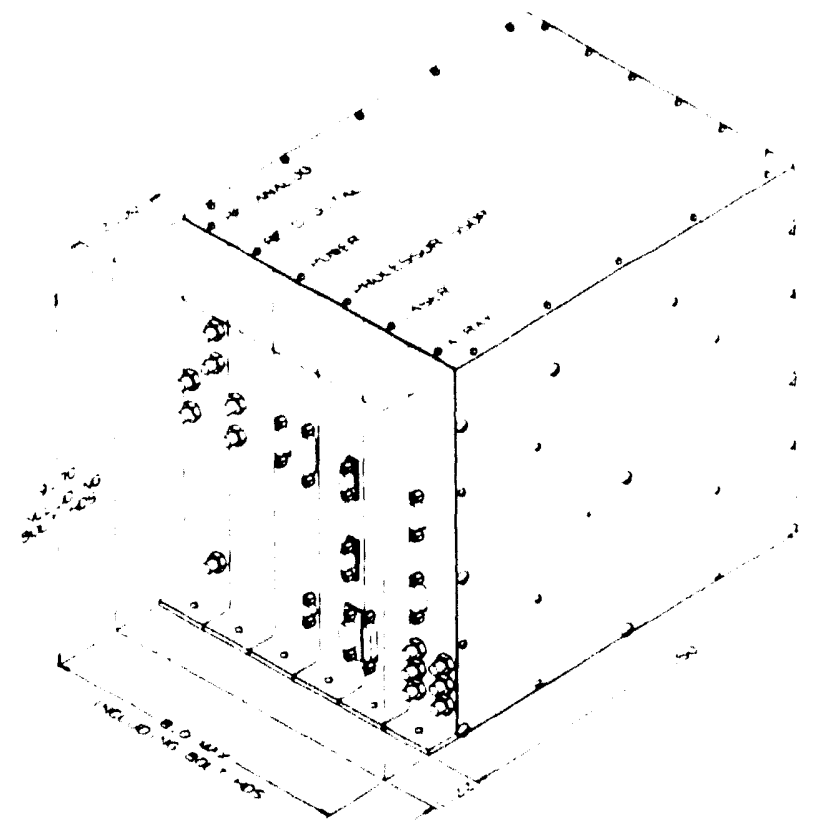

Fig. 4. SAWAFE avionics based on a slice architecture.

Fig. 5 shows a block diagram of the electronics in the $x$-ray slice. The scintillating fiber, darkening fiber, and flash $x$-ray monitor fiber are each connected to a PIN photodiode operated in current mode. The oppose end of each fiber are connected (1)

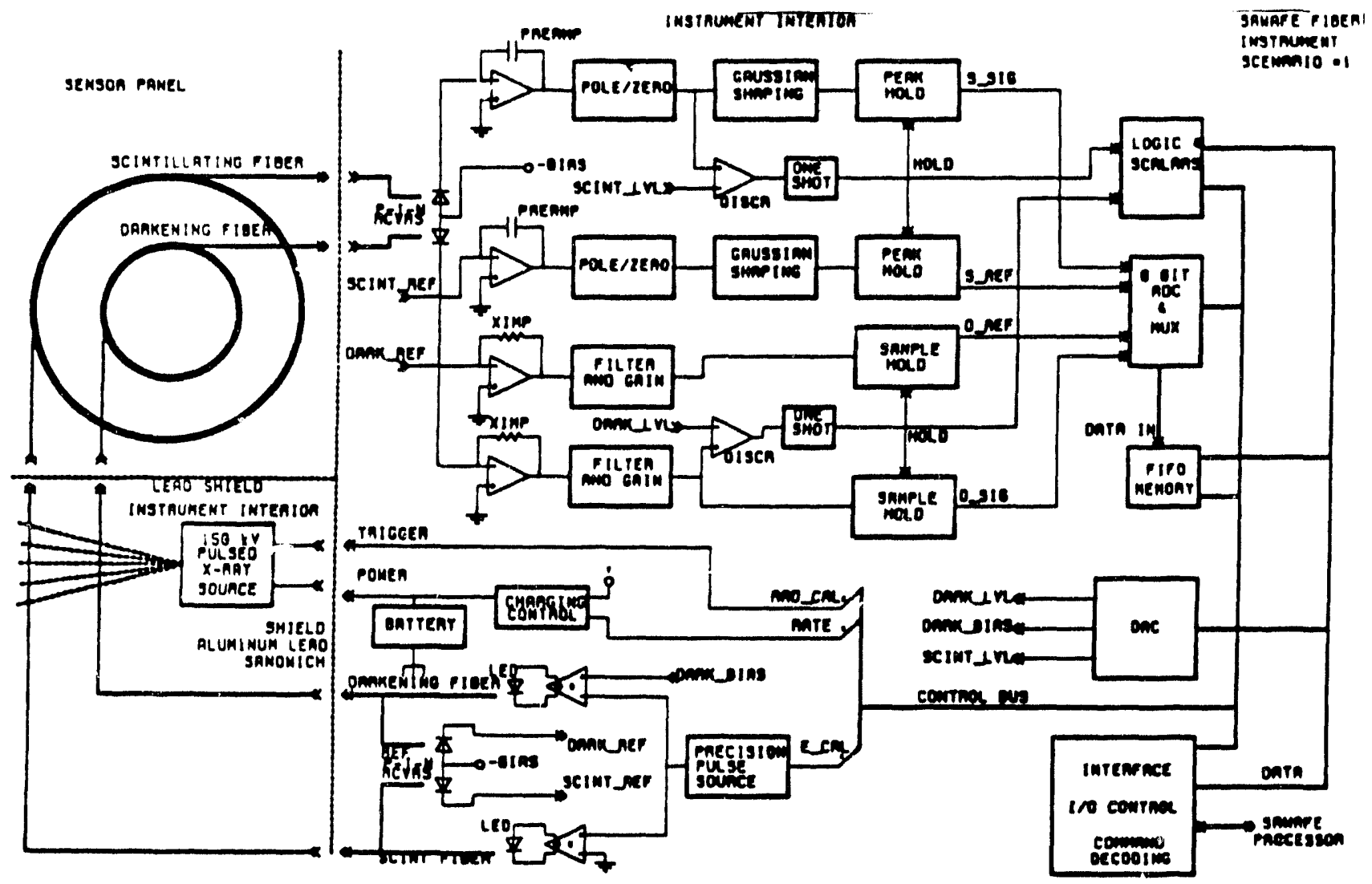

Fig. 5. Block diagram of the $x$-ray instrument electronics. 
a I.ED light source, which is referenced to a photodiode using an optical fiber beam splitter. The LEDs on the scintillating fiber and the monitor fiber are only pulsed on to test the system and to measure long-term darkening. The LED on the darkening fiber is on continuously; an $\mathrm{x}$-ray burst causes transient darkening and a momentary drop in the output from the photodiode. The dynamic range of the electronic channel on each fiber is $\approx 4) \mathrm{dB}$.

The sensitivity of the scintillating liber could be greatly increased by using a photomultiplier so that single electrons and $x$ rays could be recorded. In tests of such a design the signals were only a few photoelectrons. The fibers were very sensitive to light leaks, which required thick coatings that would increase the attenuation of low-energy $x$ rays. Such sensitivity is not required for our application.

\section{RESPONSE}

We have measured the response of the fibers over a large dynamic range. A Febetron flash $x$-ray machine at Los Alamos
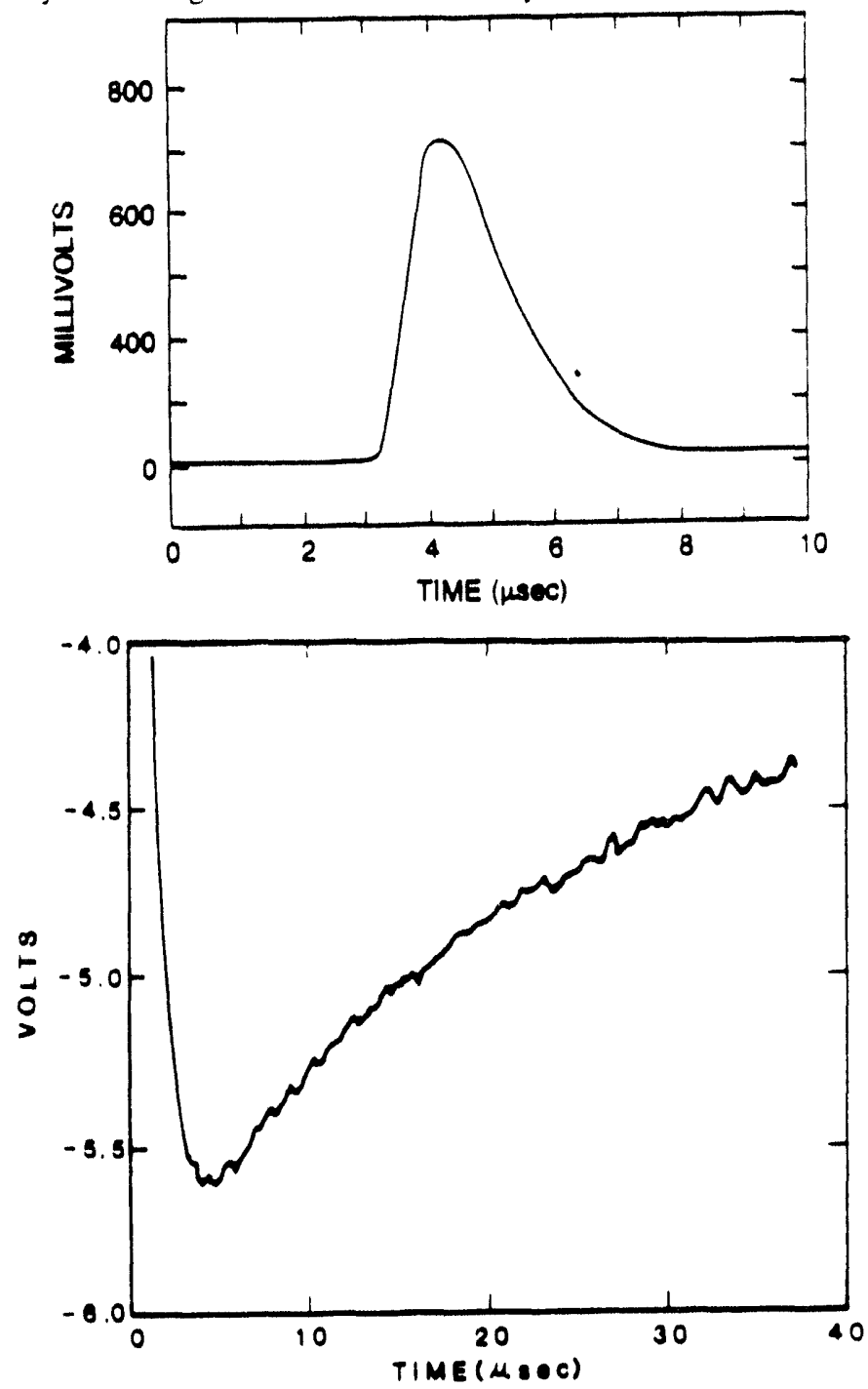

Fig. 6. Signal waverforms for a) the scintillating fiber and b) the darkening fiber. provided low dose pulses, and an electron accelerator at the Hill Air Force Base provided high dose pulses. The fact that the radiation proxluced by the accelerator is a mixture of electrons and $x$ rays is not significant because the fiber response is similar for electrons and $x$ rays. Fig. 6 shows sample waveforms from the 'wo types of fibers. Note that the the Full Width at Half MaxiIr.um (FWHM) of the scintillating tither waveform is $<2 \mu$ s whereas the FWHM of the darkening fiber waveform $1 \mathrm{~s} \approx 17 \mu \mathrm{s}$. Because the FWHM of an ESD pulse is $\approx 2 \mu \mathrm{s}$, the darkenung pulse caused by a burst of $x$ rays can be used to easily discrumunate agaunst ESD pulses. Fig. 7 shows the pulse height versus dose for the two types of fibers. For the scintillating fiber (wo channels differing by a factor of 100 in gain were used to cover the dynamic range. For the darkening fiber linac pulse widths of 50 and 500 ns were used to cover the range. The dose scale was determined by exposing $\mathrm{CaF}_{2}$ TL.Ds to multiple pulses under
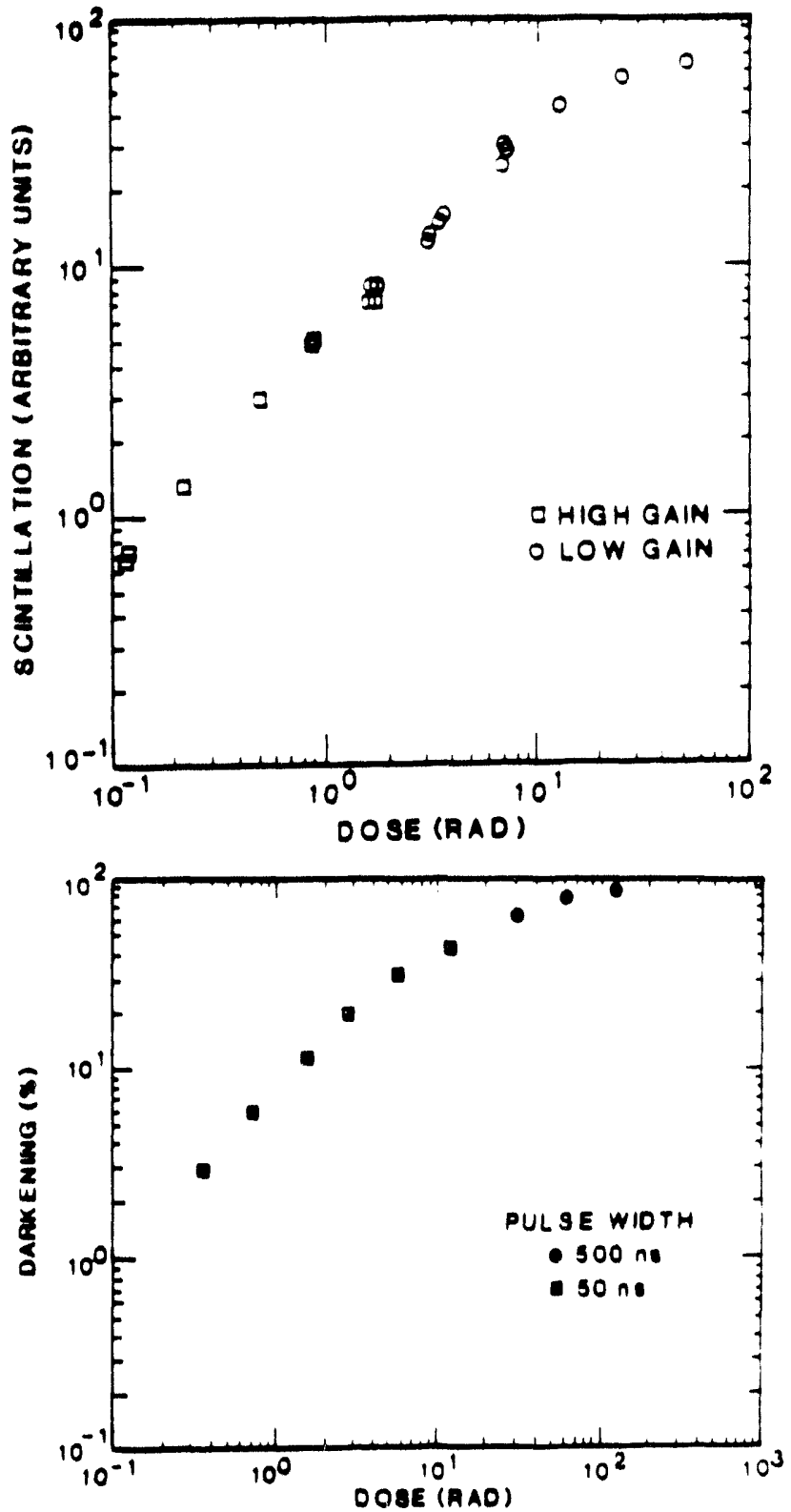

Fig. 7. Response of a) the scintillating fiber and b) the darkening fiber 
similar conditions and converting the results 10 rad(Si). The scintillating fiber is linear below 10 radi(Si) but becomes sublinear at larger doses where the ptrotodiode can not supply enough charge. The darkening fiber is linear below $3 \mathrm{rad}(\mathrm{Si})$. Both responses can be calibrated to to $>100 \mathrm{rad}(\mathrm{Si})$. The response is about $10 \%$ greater when the fibers are mounted on the panel relative to being suspended in air because of backscatter of the radiation from the panel.

We have also measured the resporse of the RADFET over a large dynamic range (Fig. 8). The unbiased RADFET was irradiated with ${ }^{60} \mathrm{Co}$ at a rate of $435 \mathrm{rad} / \mathrm{min}$. The irradiation was stopped for a few minutes, and the RADFET was biased to obtain the readings. As expected, the threshold voltage shift VT versus dose is almost linear. Fading of 10\% to $20 \%$ over a period of days after the last irradiation was observed. Correction for this should be possible with appropriate calibration.

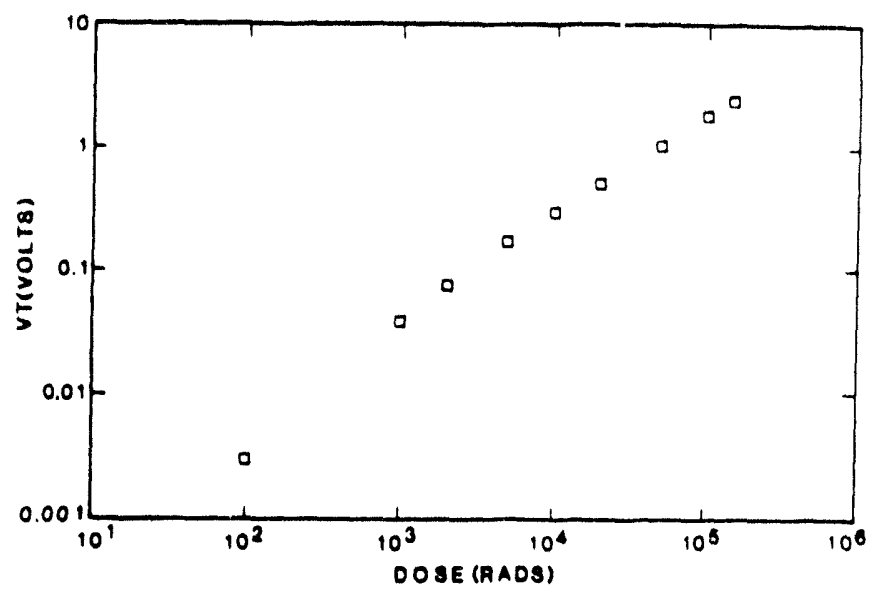

Fig. 8 RADFET response to irradiation with ${ }^{60} \mathrm{Co}$.

\section{CONCLUSIONS}

This SAWAFE instrument scheduled for launch in 1994 will demonstrate the novel, lightweight $x$-ray detector described here. The data will be transmitted to the ground for analysis, which will involve verifying the normal operation of the instrument and understanding the space background. The sensitivity of the scintillating fiber sensor could be increased by using multiple fibers in parallel to a single photodiode. The sensitivity of the darkening fiber could be increased by using a longer fiber or using a fiber with a different chemical composition. Future work on embedding the tihers and the electronics as ASIC's in the space. craft skin could lead to use of these detectors on many satellites that might be subject to attack and possibly for acquiring data in large astrophysical $x$-ray bursts.

\section{ACKNOWLEDCIEMENTS}

Lt. Col. M. Obal (SDIO) provided encouragement and funding for this work. Martin Marietta Corp. provided the panel and measured the absorptance and reflectivity. Thin Film Device, Inc., provided the ITO coating Golden Engineering, Inc., developed the flash $x$-ray unit. A. Holmes-Siedle (REM) supplied the RADFETs and valuable consultation.

\section{REFERENCES}

[1] M. Obal et ul., "The Satellite Attack Warning and Assessment Flight Experiment (SAWAFE)," in AGARD Confer. ence Proceeding 531 on Smart Structures for Aircraft and Spacecraft. Lindau, Germany, 5-7 October 1992, pp.7:1-13.

[2] P. B. Lyons, "Fiber Optics in Transient Radiation Fields." SPIE vol. 541, pp. 89.96, 1985.

[3] G.J. Berzins, J.E. Valencia, H. E. Felthauser, J. E. Nanevicz. and J. S. Thayer, "Identification and Solution of a Charging Problem in a High-Altitude Detector," in Proceedings of the Spacecraft Charging Technology Conference, Monterey, California, 31 October - 3 November 1989, pp. 111-119.

[4] K. L. Giori, R. C. Adamo, J. E. Nanevicz, and J. Kositsky, "Laboratory Studies of Spacecraft Charging Mitigation Techniques," ibid., pp. 159-165.

[5] L. J. Leger, private communication.

[6] A. F. Whitaker, R. Kamenetzky, M. M. Finckenor, and J. K. Norwood. "Atomic Oxygen Effects on LDFF Experiment A0171," in Second Post-Retrieval Symposium. NASA Conference Publication 3194. San Diego. CA, June 1992, pp. 1125-1135.

[7] J. Gregory, private communication.

[8] A. Holmes-Siedle and L. Adams, "RADFET: A Review of the Use of Metal-Oxide-Silicon Devices as Integrating Dosimeters," Radiat. Phys. Chem., vol. 28, No. 2, pp. 235. 244, 1986.

[9] L. Adams et al. "Measurements of SEU and Total Duse in Geostationary Orbit under Normal and Solar Flare Condi. tions," IEEE Trans. Nucl. Sci., vol. NS-38, No. 6, pp. $1686-$ 1692. December 1991. 

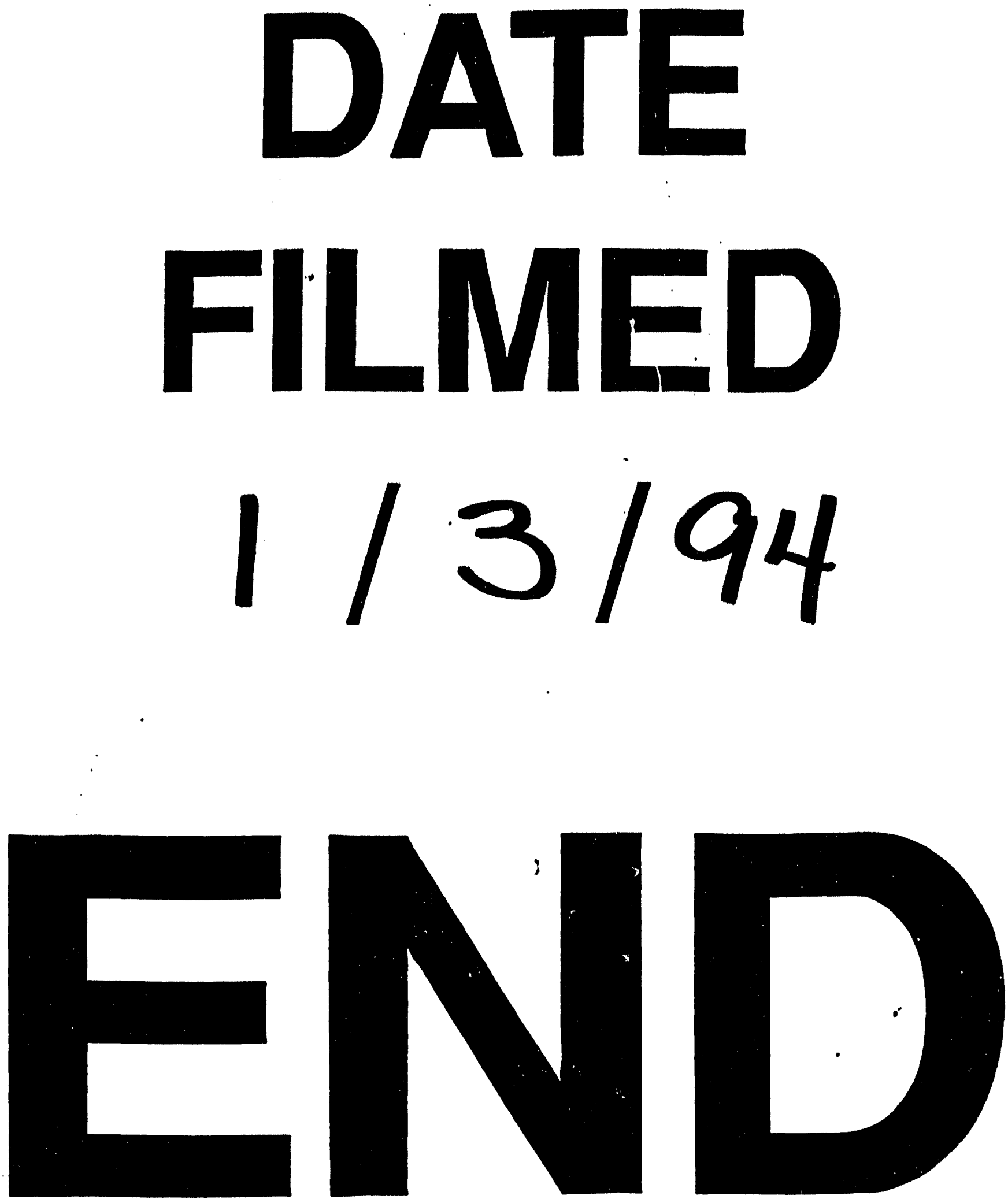
